\title{
Communication Strategies for Various Types of Swallowable Telemetry Capsules
}

\author{
Jin-Ho Cho and Sang Hyo Woo \\ School of Electrical Engineering and Computer Science, \\ Kyungbook National University, \\ South Korea
}

\section{Introduction}

In this chapter, introducing some of the ideas, potentialities, and limitations of swalowable telemetry capsule systems. The telemetry systems were widely used for animal research while the subject can do its regular activities [1-9]. Therefore, it is an ideal method to collect the data of migration path and environmental data. In order to collect the data, the telemetry system has to be attached or implanted to the subjects and transmits the signal throughout the antenna. For the human patients, most of physiological signal from outside of the body did not need telemetry systems, because the signal was easily distorted when the patients were moving. Therefore, the telemetry systems are used when the device is implant into the patients and then collect the data. Since the implantation of the device is extremely difficult work, using the telemetry system is limited for scientific researches and a commercial medical telemetry device was not advent.

Since the implantable telemetry systems is limited by the regulations and safety issue, the scientists look forward to develop a disposable capsule that resemble a medical pill and automatically measure the various philological data after swallow it. There are many frontier researches about the telemetry capsules. Some of the capsule measured the intraluminal pressure from inside of the gastro intestine while the capsule goes naturally flow toward to aboral direction [10-14]. Since the physician gets the intraluminal data, it was hard to assume a location of the capsule such as the capsule is in the middle of a duodenum or jejunum?

Another capsule can measure $\mathrm{pH}$ signals from the gastro intestine. This capsule provides the meaningful data to diagnosis many diseases such as the gastroesophageal reflux. These capsules also measure the $\mathrm{pH}$ signal while it is naturally flow and does not provide location information. While most of the capsules was measuring the signal when the capsule was naturally flow toward to aboral direction, a bravo capsule can stop at the esophagus and measuring the $\mathrm{pH}$ difference [15-19]. Other capsules measures the core temperature [20, 21], which is a bit higher than skin temperature.

Unlike above applications, a capsule endoscopy is a revolutionary product that captures inside of the gastro images and transmits it throughout the RF transmitter [22-26]. In order to get clear images, the data rate of the RF transmitter has to be sufficiently high while the power consumption is still low that could be active by small coin batteries. The frontier of this field is Given Image company products and it could monitor not only the small intestine but also the esophagus and colon. 
Due to success of the capsule endoscopy, there are many trails to develop the capsule that has surgical operation, medical treatment, and locomotion abilities [27-33]. Most of researches are focused to give locomotion ability by using a magnet, actuator, and electrical stimuli. The aim of locomotion research is to observe a suspicious area because the capsule is naturally goes down to the aboral direction. Other researches do increasing friction to stop the capsule at the suspicious area [34, 35]. Also, there are many interesting capsules are developing such as a bleeding detection [36], assembling capsule[37], and biopsy [37].

From above description, application of the swallowable telemetry capsule is abundant and it is rapidly cutting its edges. In order to transmit the physiological data or control the capsule, a telemetry system is essential part for stable module. In this chapter, a basic telemetry methods are describe in 2.1 to 2.2 and describe important points for swallowable capsule in the 2.6. Therefore, the reader who is familiar of a communication technique should skip the $2.1 \sim 2.5$ and read the 2.6 directly.

\section{Telemetry system}

Telemetry is a technology that allows remote measurement, control, and reporting of information. In order to transmit the data throughout radiation, concept of the modulation have to be known.

\subsection{Modulation methods}

Modulation is the process of varying one or more properties of a high-frequency periodic waveform, called the carrier signal, with respect to a modulating signal. Fig. 1 shows block diagram of the modulation where the signal is modulated by the carrier signal. There are the three key parameters of the modulation, which is amplitude, phase, and frequency. Typically a high-frequency sinusoid waveform is used as carrier signal, but a square wave pulse train may also occur. Fig. 2 (a) depicts the modulation result that the baseband signal $(m(t))$ is up converted by carrier frequency $\left(\cos \left(w_{c} t\right)\right)$. The negative frequency is generated and bandwidth of the signal is remained.

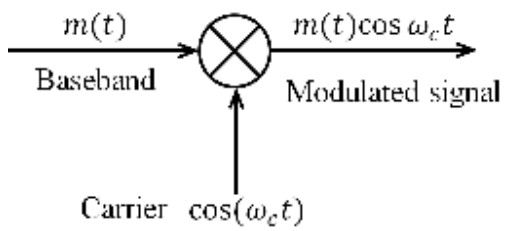

Fig. 1. Block diagram of the modulation.

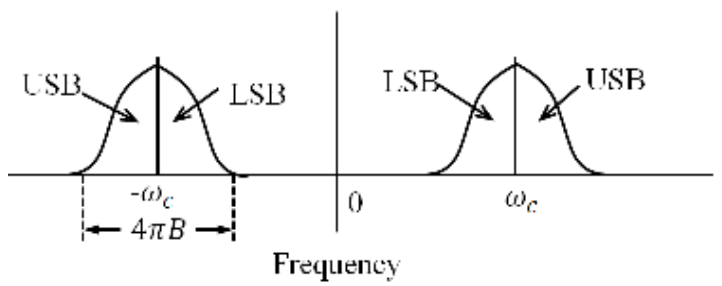

Fig. 2. Spectrum of frequency up converting. 
Fig. 3 depicts common analog modulation methods that is known as amplitude modulation (AM), frequency modulation (FM), and phase modulation (PM). The latter two types of modulation are similar, and belong to the class of modulation known as the angle modulation.

The AM is characterized by the fact that amplitude of carrier signal is varied in proportion to the baseband signal. In the fig. 3 (c) depicts modulated AM signal and it could be easily see the amplitude of the signal is varying with the baseband signal. The FM conveys information over a carrier wave by varying its instantaneous frequency. In the fig. 3 (d) depicts the frequency of the carrier signal is changed from the baseband signal. The PM is a form of modulation that represents information as variations in the instantaneous phase of a carrier wave. In the fig. 3 (e) depicts that the phase of the signal is varying with the baseband signal.

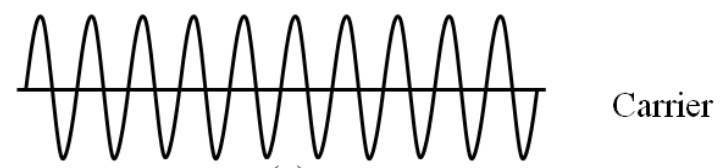

(a)
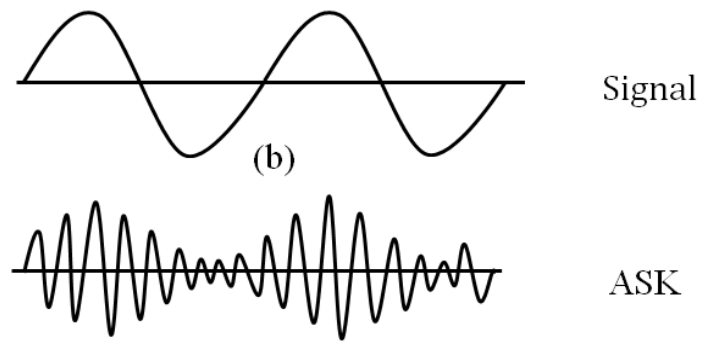

ASK

(c)

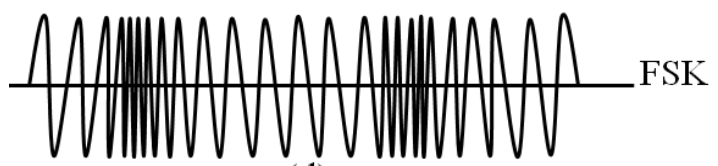

(d)

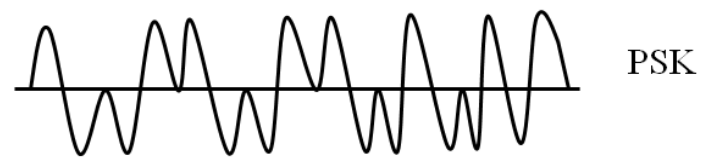

(e)

Fig. 3. Simple example of the modulated signal.

With using analog modulation system, the super heterodyne system is widely used due to its simplicity, cheap, and high performance. Fig. 4 depicts the super heterodyne system that uses frequency mixing or heterodyning to convert a received signal to a fixed intermediate frequency (IF). With using the IF, it is easily tuning the channel and can reduce performance of the band filters. 


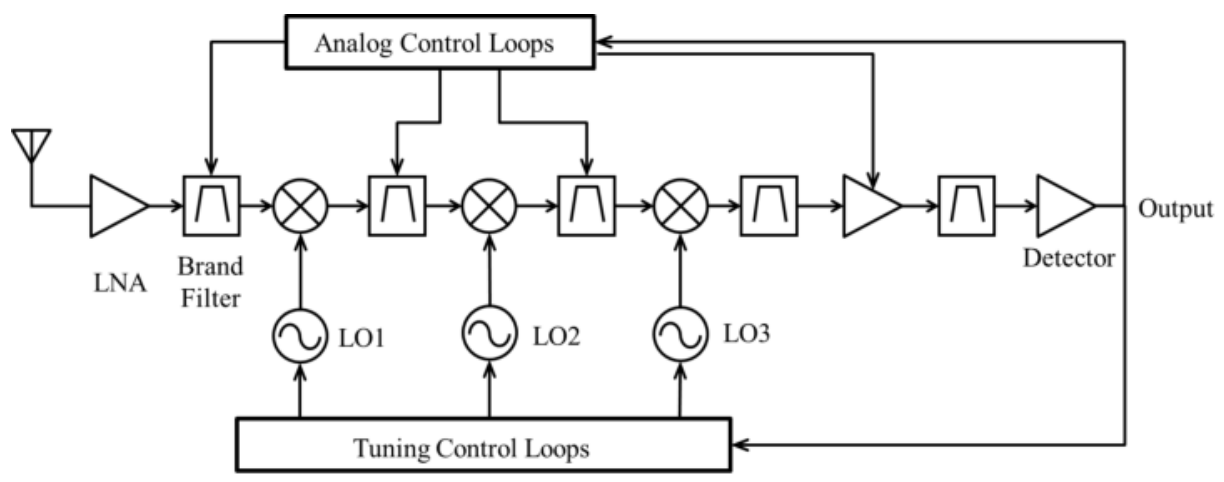

Fig. 4. Block diagram of traditional super heterodyne detection system.

Unlike analogy modulation, the digital modulation uses digitalized baseband signal and inphase/quadrature (I/Q) modulator, which can actually create the AM, FM, and PM modulation with in one hardware. The fig. 5 depicts the I/Q modulator and demodulator system that has two mixer with same carrier signal with -pi/2 lag. The I/Q modulator can modulate a carrier with a waveform that changes the carrier's frequency slightly; you can treat the modulating signal as the phasor. It has both a real and an imaginary parts, or an inphase (I) and a quadrature (Q) part. Now construct a receiver that locks to the carrier, and you can decipher information by reading the I and $Q$ parts of the modulating signal.

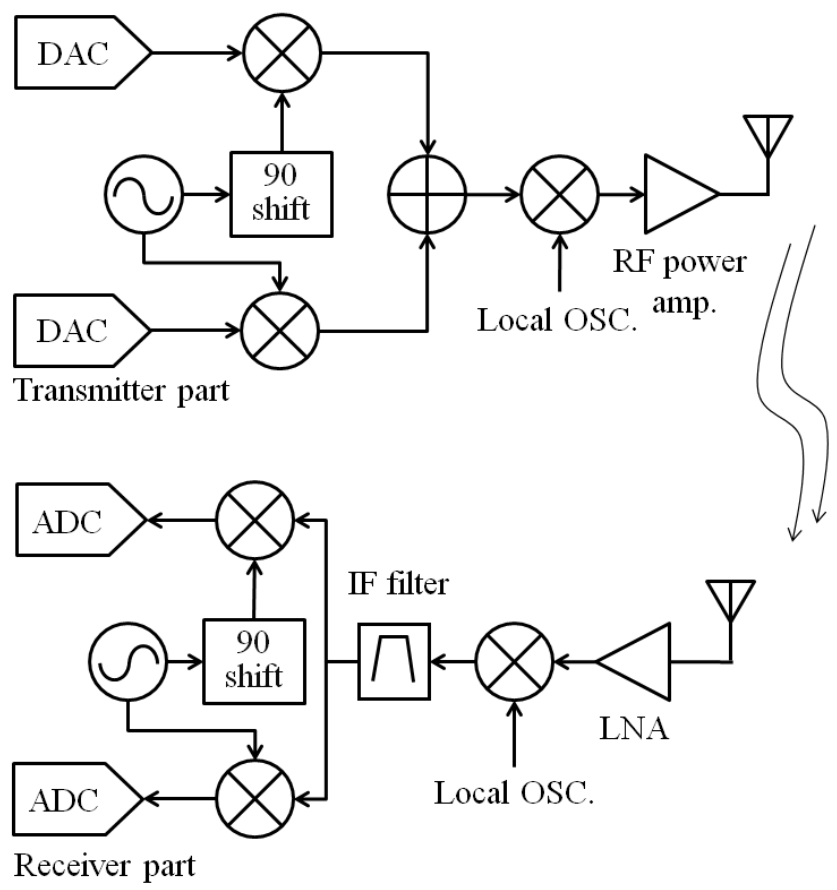

Fig. 5. I/Q modulator and demodulator. 
With help the I/Q modulator, various digital modulation is generated such as BPSK, O-PSK, GMSK, and QAM. The Fig. 6 depicts that the BPSK signal that vary with input baseband signal. Unlike analogy modulation, the digital modulation uses digitalized baseband signal and the modulated signal is discontinued.

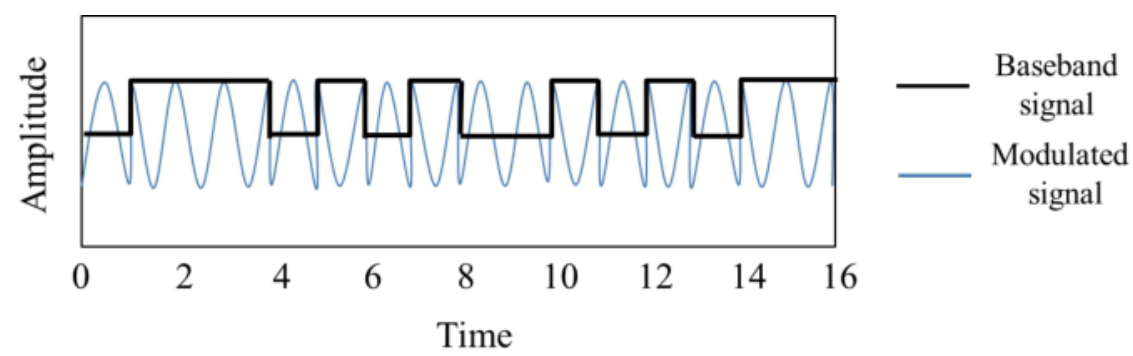

Fig. 6. I/Q modulator and demodulator.

\subsection{Spread spectrum}

A spread-spectrum system is a process other than the information signal to expand, or spread, the bandwidth of the signal. The spread-spectrum method is that breaks the data signal into little pieces using some kind of code, and the transmitted signal with wide bandwidth. Therefore, it is hard to tap and find the signal. There are four types are used for spectrum spreading such as direct sequence, frequency hopping, time hopping, and frequency chirp.

Fig. 7 depicts a direct sequence spread spectrum (DSSS) technique is that multiply the data by the pseudonoise (PN) code, and spreading the energy of the original signal into a much wider band. The spread signal resemble the white noise, which looks like wide band noise, and it could be dispreading when PN code is known.

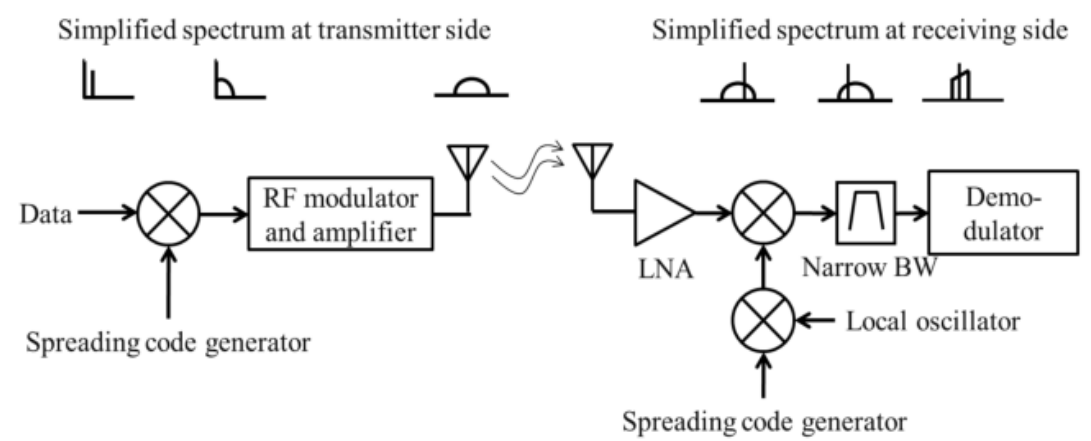

Fig. 7. Diagram of direct-sequence spread spectrum.

Another method to spread spectrum is using frequency-hopping spread spectrum (FHSS). The FHSS is a method of transmitting radio signals by rapidly switching a carrier among many frequency channels, using a pseudorandom sequence. Fig. 8 depicts the block diagram of the FHSS. Unlike the DSSS, the spectrum the FHSS shows vary shape impulses and disappear immediately. 


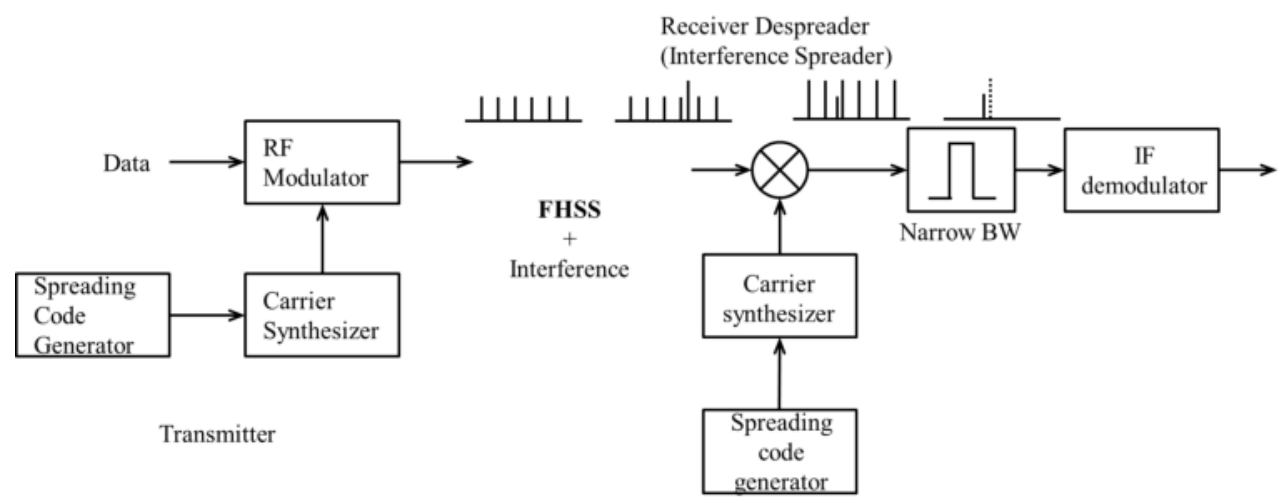

Fig. 8. Block diagram of frequency-hopping spread spectrum.

Orthogonal frequency-division multiplexing (OFDM) is a frequency-division multiplexing (FDM) scheme used as a digital multi-carrier modulation method. A large number of closely-spaced orthogonal sub-carriers are used to carry data. The fig. 9 depicts the difference between the spectrum of FDM and OFDM. Since the FDM have to avoid the superposition its frequency band to other, the OFDM use the sub-carrier are orthogonal to each other.

Five FDMA Channels

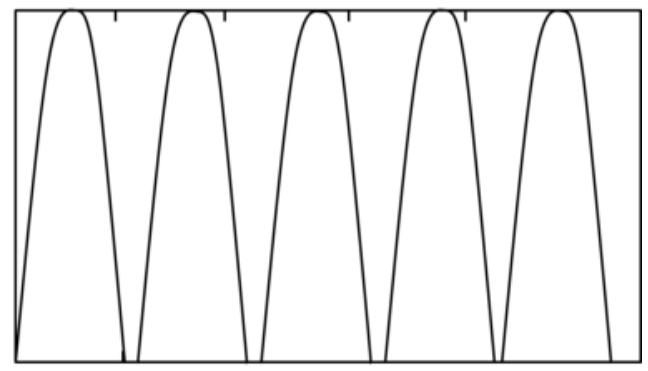

Frequency

Five OFDM Channels

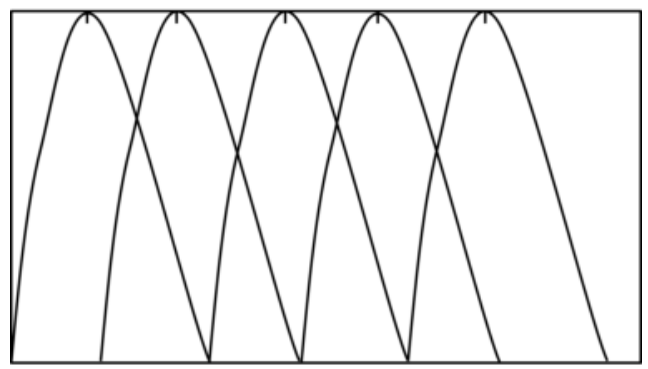

Frequency

Fig. 9. Spectrum difference of the FDM and OFDM. 
The OFDM use an inverse FFT to compute parallel data for giving a set of complex timedomain samples. These samples are then quadrature-mixed to passband in the standard way. The real and imaginary components are first converted to the analogue domain using digital-to-analogue converters (DACs); the analogue signals are then used to modulate cosine and sine waves at the carrier frequency, respectively. These signals are then summed to give the transmission signal. Above descriptions are depicted in the fig. 10.

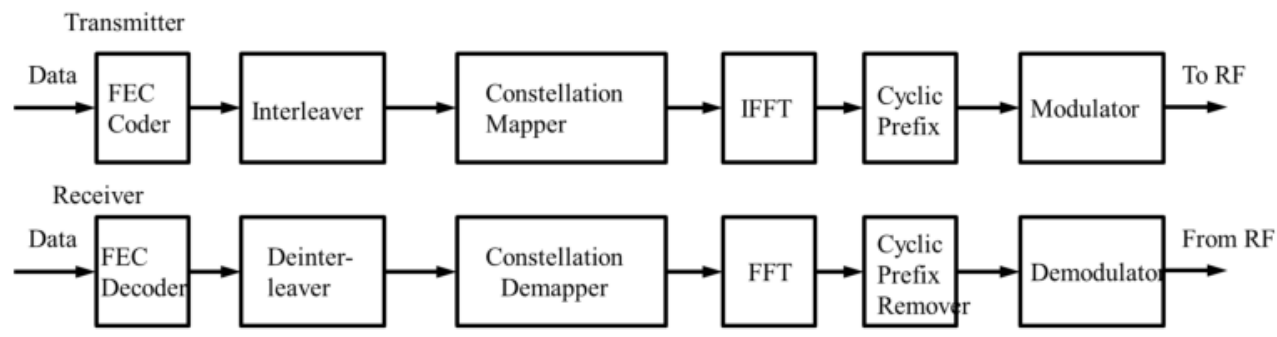

Fig. 10. Block diagram of the OFDM.

\subsection{Software-Defined Radio spread spectrum}

A software-defined radio system (SDR) is a radio communication system where components that have been typically implemented in hardware such as mixer and detectors. The strong advantage of the SDR is that it can modulate/demodulate various type of communication without additional hardware. The fig. 11 depicts the concept of the SDR that it could receive various modulated signal by one hardware.

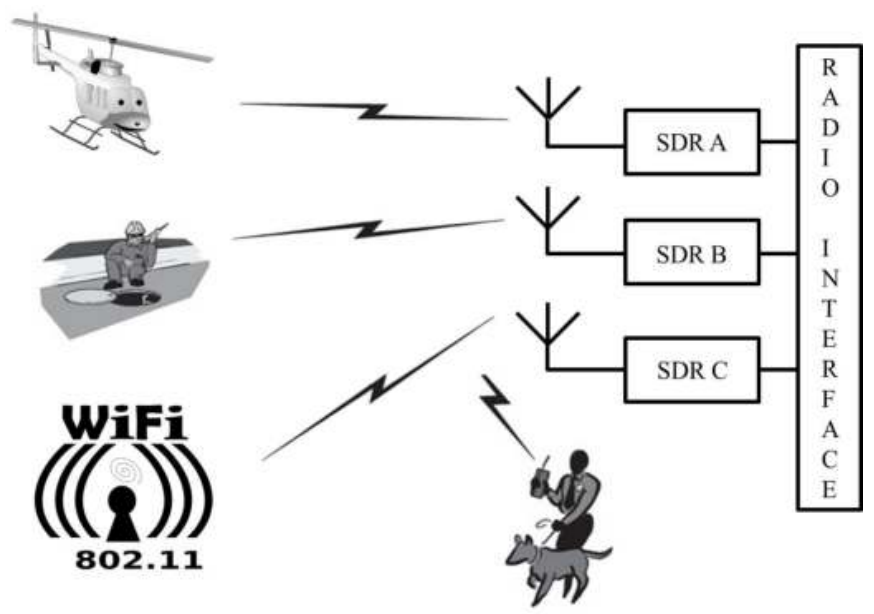

Fig. 11. Concepts of the SDR.

Since the concept of the SDR can directly receive the analog signal from the antenna, the ideal scheme is not completely realized because of limits of the analog to digital conversion (ADC). The ADC speed and resolution is not high enough to receiver RF or IF stage signal. Therefore, most of low end SDR use super-heteroine structure and it is depicts in the Fig. 12. 
Recently, many high speed and accuracy ADC is developed and eliminate IF stage and directly receive the signal from IF signal.

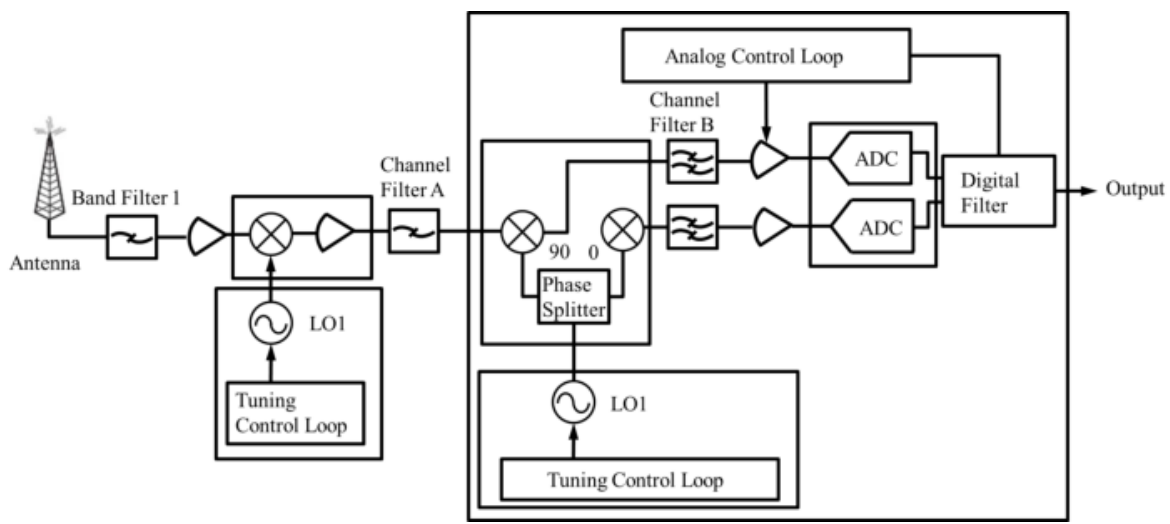

Fig. 12. Block diagram of the SDR.

\subsection{Ultra-wideband communication}

Ultra-wideband is a radio technology that can be used at very low energy levels for shortrange high-bandwidth communications by using a large portion of the radio spectrum. The UWB uses high frequency with low power density which is typically $-41 \mathrm{dBm} / \mathrm{MHz}$ and does not arrowed to use frequency below $2.6 \mathrm{GHz}$ to reduce possibility of collision. The fig. 13 depicts the FCC indoor mask which is limitation of RF power for the UWB.

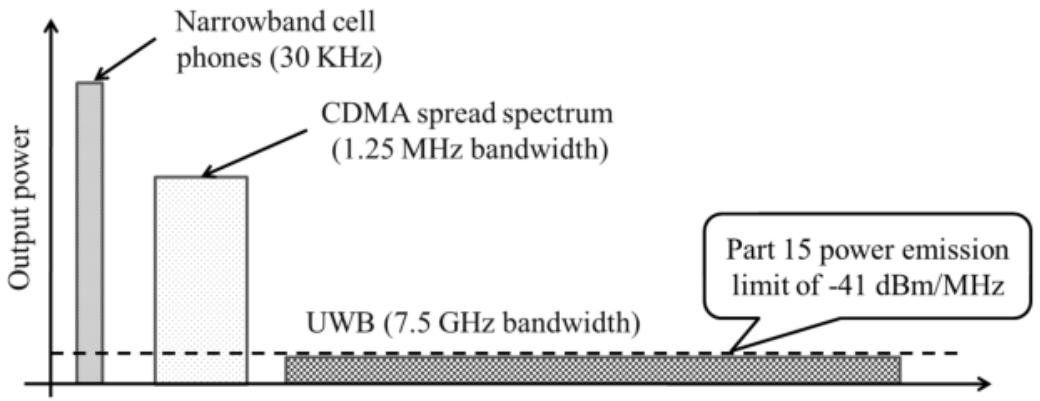

Frequency

Fig. 13. Band width comparison between commercialized communication and UWB.

In order to follow the regulation, most of the UWB signal is generated by $n$th derivative of the Gaussian pulse shape. The fig. 14 depicts multiple pulse shapes of the UWB and its equation is shown as

$$
p(t)=\frac{A}{\sqrt{2 \pi \sigma^{2}}} e^{\left(-t^{2} / 2 \sigma^{2}\right)}
$$

Where $A, t$, and $\sigma$ are amplitude, time and spread of the Gaussian pulse. 
Hence the time which the signal is actually transmitting is very short, the power consumption of the UWB is very low and it is easy to achieve the time division multiplex (TDM).

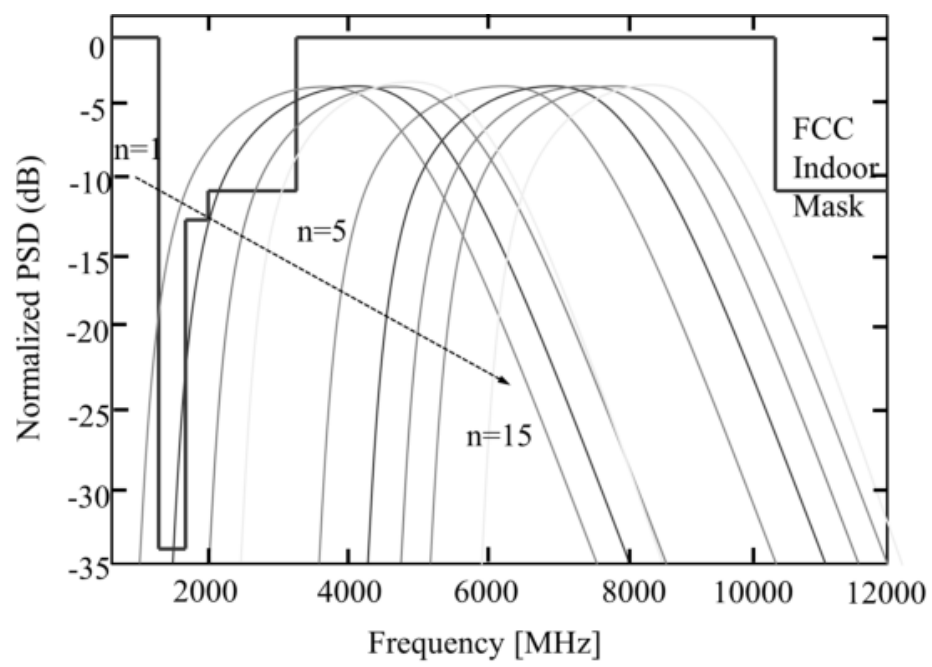

Fig. 14. PSD of higher order derivatives of the Gaussian pulse for UWB indoor systems.

Fig. 15 (a) depicts a conventional RF communication and Fig. 15 (b) depicts a UWB communication system. Unlike the conventional RF transceiver, the UWB requires less hardware and can easily convert the analog signal to digital.

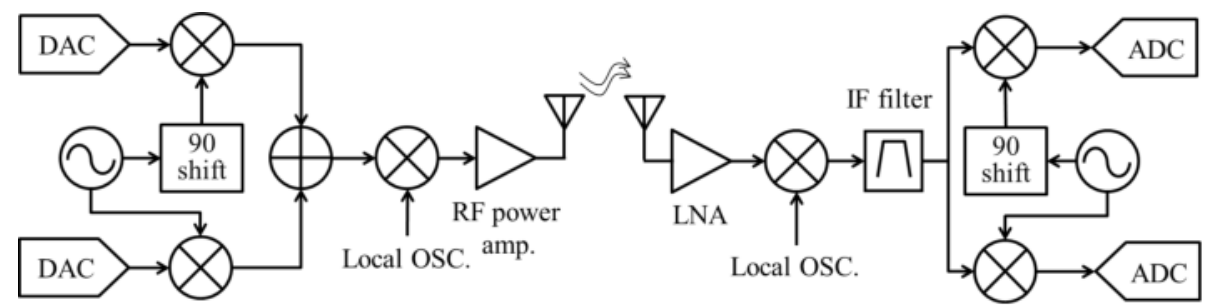

Transmitter part

Receiver part

(a)

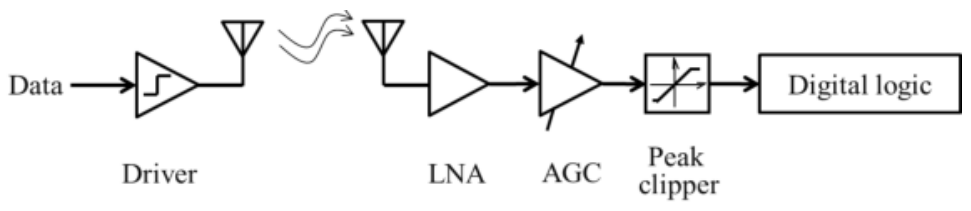

(b)

Fig. 15. UWB communication. (a) Conventional communication. (b) UWB communication. 


\subsection{Body Area Network}

A Body Area Network (BAN) is a term used to describe the application of wearable computing devices that transmit data throughout the human body. Since the human body is a much better transmission medium comparing than air, the transceiver can be activated by using low power. Therefore, the information can be transmitted to another person when two people are shaking hands. Since the concept of the BAN is for communication throughout the surface of the skin, there is a trail for using this technology for the capsule endoscopy.

The company Intromedic reported on a capsule that transmits data by using a BAN. The capsule has two electrodes that can touch the inside of the gastrointestinal tract and transmit the data throughout the human body. A receiver was attached at the surface of the human body using the ECG electrodes.

\subsection{Application of a swallowable capsule}

In order to design a telemetry system, the RF frequencies have to be chosen based on the attenuation, data rate, maximum permissible exposure (MPE), and antenna efficiency. Since the human body mostly consists of saline, the RF power is attenuated in various parts of the human body. Fig. 16 depicts the attenuation constants for various parts of the human body. The attenuation is proportionally increased with frequency. Among the various parts of the human body, the small intestine shows the highest attenuation and the fat shows the lowest attenuation factor.

An application such as capsule endoscopy, which captures the image from the inside of the gastrointestinal tract and wirelessly transmits it to the outside, focuses on penetrating the RF power from the small intestine. Unfortunately, the small intestine attenuates a great deal of RF power and it is thus necessary to transmit a high RF power from the small capsule. High RF power will reduce the working time of the capsule endoscopy, and the MPE should be taken into consideration.

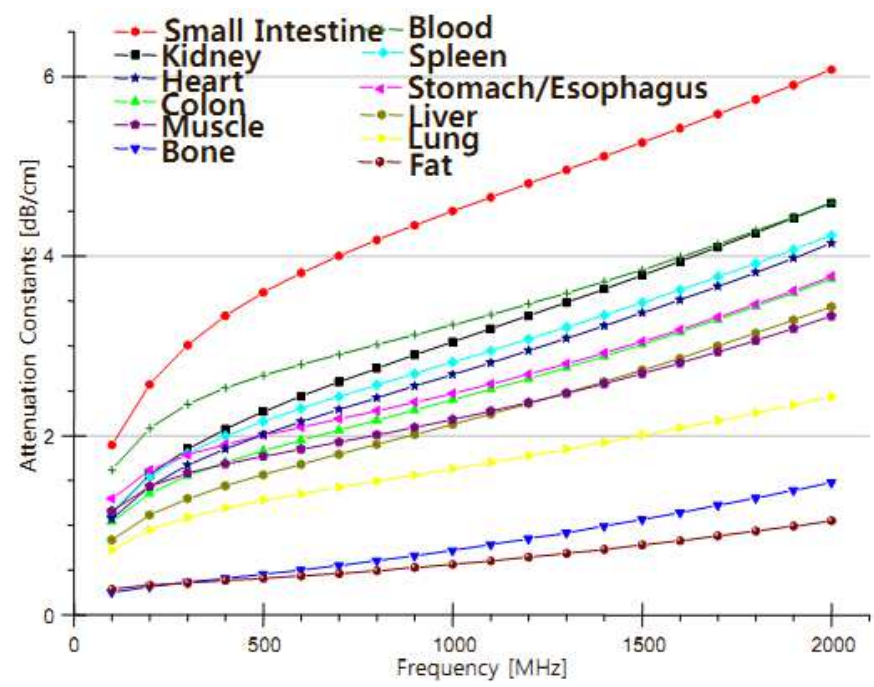

Fig. 16. The attenuation constants for various parts of the human body. 
The MPE is the highest power or energy density of an RF source that is considered safe, i.e. that has a negligible probability for creating damage. Since the MPE is regulated from the outside of the body, it could be used as a guideline for the amount of RF radiation inside the body.

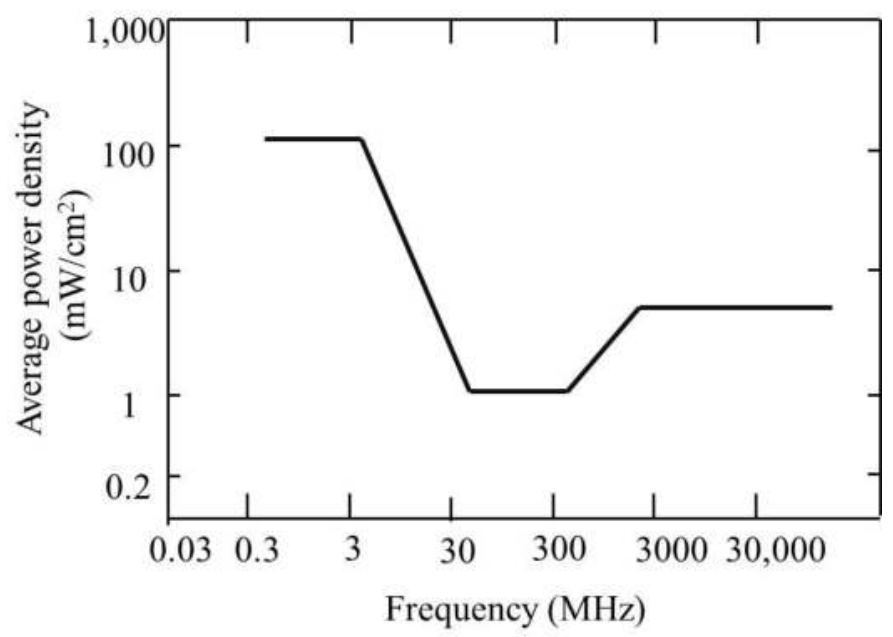

Fig. 17. The maximum permissible exposure regulation.

In order to determine the RF band, the body attenuation, MPE, and data rate have to be considered. Since the antenna efficiency is extremely low at low frequencies ( $<100 \mathrm{MHz})$, the length of the antenna has to be longer than the size of the small pill. However, the low frequency modulation requires less power consumption and radiation power because the human body does not attenuate the low frequency. Therefore, early capsule type telemetry systems were designed to use the FM method and used a long and flexible antenna. Since early telemetry systems did not require a high data rate, this was sufficient except for the repulsion of its shape.

With the advent of capsule endoscopy, the data rate has to be increased so as to be sufficient enough for transmission of gastrointestinal images. Fig. 18 shows an example of capsule endoscopes. The analog type can transmit the National Television Standards Committee (NTSC) format, which is widely used for analog TV transmission, and the physician can monitor the inside of the gastrointestinal tract as if watching an analog television. Since the NTSC uses the analog transmission technology, it could provide a high fame rate (30 frame/s) but it is weak to channel noise; further, restoration of the data is impossible. Fig 18 (b) shows digital type capsule endoscope that could transmit $640 \times 480 \times 8$ resolution images by using a digital transmitter. Since a digital receiver can restore the data from environmental noises, the frame rate of the capsule is reduced to 1 frame/s. Fig. 18 (c) shows images taken from the ileum and esophagus by using a digital type transmitter capsule.

In order to transmit at a high data rate, the RF frequency has to be increased so as the make the antenna effective. For capsule endoscopy, the 430 and $1200 \mathrm{MHz}$ the industrial, scientific and medical (ISM) bands are widely used to transmit the signal. These bands can transmit higher data rate than the FM band and the human body attenuation is moderate enough to 
allow the signal to penetrate the body. Also, the size of the antenna should be small enough that it can be inserted into the capsule. For these reasons, the Federal Communications Commission (FCC) decided to create the Medical Implant Communication Service (MICS) for the use of the frequency band between 402 and $405 \mathrm{MHz}$ for communication with medical implants. It allows bidirectional radio communication with pacemakers or other electronic implant devices.

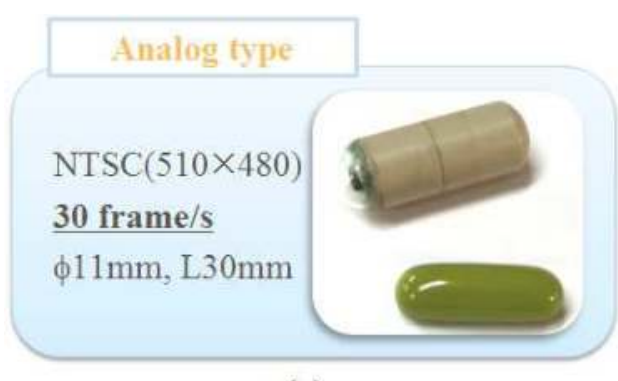

(a)

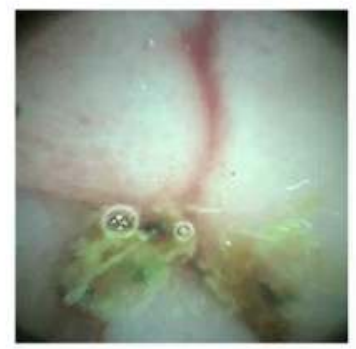

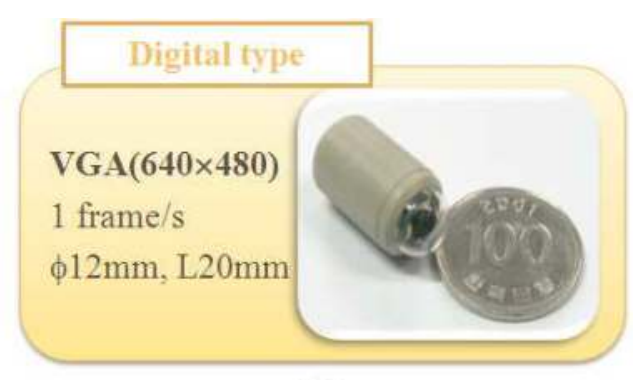

(b)

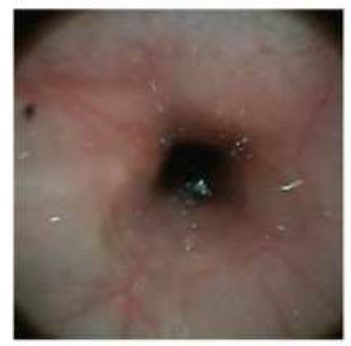

(c)

Fig. 18. Example of capsule endoscopy. (a) NTSC format transmitter. (b) VGA resolution transmitter. (c) Image taken from the VGA resolution transmitter capsule.

$2.4 \mathrm{GHz}$ is widely used for commercial WLAN, and there are many commercial antennas and transceivers for it. Unfortunately, the body attenuation at the $2.4 \mathrm{GHz}$ is too high that it could attenuate up to $-50 \mathrm{dBm}$ at a $15 \mathrm{~cm}$ body thickness. Therefore, the $2.4 \mathrm{GHz}$ band is not suitable for uses with implants or swallowable telemetry systems. Table 1 summaries the RF frequency efficiency of the various RF bands.

Most swallowed capsule designs have used conventional modulation such as FM or AM because of their simplicity. Since capsule telemetry is not widely used, encrypt and spread spectrums were not taken into account. Also, the concept of the UWB fits well with capsule endoscopy because the transmitter does not require a large space and power consumption is lower than that of the conventional transmitters. However, the human body attenuates high frequency signals, and this cannot be overcome by using equalization. There is one trial using UWB for capsule endoscopy, and the frequency was reduced to $800 \mathrm{MHz}$ and a transceiver was implemented. Even though this proposed system violates the regulation of the UWB, it could be useable if the upper frequency were limited. 


\begin{tabular}{|c|c|c|c|c|c|}
\hline Comparatives & $\begin{array}{c}300 \mathrm{MHz} \\
\text { Range }\end{array}$ & $\begin{array}{l}400 \mathrm{MHz} \\
\text { Range }\end{array}$ & $\begin{array}{l}900 \mathrm{MHz} \\
\text { Range }\end{array}$ & $\begin{array}{c}1200 \mathrm{MHz} \\
\text { Range }\end{array}$ & $\begin{array}{c}2400 \mathrm{MHz} \\
\text { Range }\end{array}$ \\
\hline Safety level & Best & & Best & & Moderate \\
\hline $\mathrm{MPE}\left[\mathrm{dBm} / \mathrm{cm}^{2}\right]$ & 0 & 1.25 & 4.78 & 6.02 & 6.99 \\
\hline Attenuation & Best & & Good & & Worst \\
\hline $\begin{array}{c}15 \mathrm{~cm} \text { Body } \\
\text { attenuation }\left[\mathrm{dB} / \mathrm{cm}^{2}\right]\end{array}$ & 14 & 15 & 20 & 24 & 41 \\
\hline $\begin{array}{c}\text { Power } \\
\text { transmission }\end{array}$ & Best & & Good & & Worst \\
\hline Availability & & ISM Band & ISM Band & & ISM Band \\
\hline $\begin{array}{l}\text { Antenna Size } \\
\text { efficacy }\end{array}$ & Worst & & Good & & Best \\
\hline
\end{tabular}

Table 1. RF frequency efficiency of the various the RF bands

Another method is using an OFDM that can transmit a large bandwidth within a limited frequency band, but it requires FFT/IFFT modules that consume too much power. Since the capsule uses small batteries that typically have a capacity of less than $100 \mathrm{mAh}$, it is not easy to implement a low power FFT/IFFT block.

The SDR method is good for the swallowable capsule because it can support the various types of transmission signals. When the SDR is developed, patients will only need to receive signals in one receiver from many transition sources. When the protocols of swallowable capsule are open, this could become possible.

Table 2 summarizes various types of telemetry systems for capsules. Various modulation methods, frequencies, and RF power levels were used for various applications. Usually, FM modulation is used for moderate data rates and AM is used for simple and low power purposes. In additionally, SDR and UWB appear feasible but their details have not been fully described.

\begin{tabular}{|c|c|c|c|c|c|}
\hline Reference & $\begin{array}{c}\text { Frequency } \\
(\mathrm{MHz})\end{array}$ & $\begin{array}{c}\text { Data rate } \\
(\mathrm{kbps})\end{array}$ & Modulation & $\begin{array}{c}\text { Power } \\
\text { consumption } \\
(\mathrm{mW})\end{array}$ & $\begin{array}{c}\text { RF power } \\
(\mathrm{dBm})\end{array}$ \\
\hline Thone et al. & 144 & 2000 & FSK & - & -18 \\
\hline Chen et al. & 433 & 267 & FSK & 24 & - \\
\hline Wang et al. & - & - & AM & 125 & Variable \\
\hline Kfouri et al. & UHF & 250 & - & - & - \\
\hline Park et al. & 315 & - & AM & - & - \\
\hline $\begin{array}{c}\text { Mackay } \\
\text { et al. }\end{array}$ & 433 & - & FM & 15.5 & - \\
\hline Woo et al. & 1200 & 2000 & SDR & - & - \\
\hline Lee et al. & 1200 & 2000 & FSK & 29.7 & - \\
\hline Intromedic & - & - & $\begin{array}{c}\text { Manchester } \\
\text { code }\end{array}$ & - & - \\
\hline
\end{tabular}

Table 2. Various types of applications of swallowable telemetry capsule 


\section{Conclusion}

In this chapter, brief explanations of modern communication strategies are explained and the limitations of their use in swallowable telemetry systems are described. Selections of the RF band and modulation methods are described and compared with each other. Since the human body attenuates high frequency RF power, their use in sophisticated communication is limited.

\section{Acknowledgment}

I'd like to thank Qun Wei and Zia Moth-Un-Din for their support of drawing the pictures. This book was supported by a grant of the Institute of Biomedical Engineering Research, Kyungpook National University, Republic of Korea.

\section{References}

[1] Dinslage, S., J. McLaren, and R. Brubaker, Intraocular pressure in rabbits by telemetry II: Effects of animal handling and drugs. Investigative Ophthalmology \& Visual Science, 1998. 39(12): p. 2485-2489.

[2] Hawkins, P., Telemetry in the field: Practical refinements to improve animal welfare. Comparative Biochemistry and Physiology a-Molecular \& Integrative Physiology, 2007. 146(4): p. S84-S84.

[3] Johnson, D.S., et al., Continuous-time correlated random walk model for animal telemetry data. Ecology, 2008. 89(5): p. 1208-1215.

[4] Johnson, D.S., et al., A general framework for the analysis of animal resource selection from telemetry data. Biometrics, 2008. 64(3): p. 968-976.

[5] Kong, W., et al., A semi-implantable multichannel telemetry system for continuous electrical, mechanical and hemodynamical recordings in animal cardiac research. Physiological Measurement, 2007. 28(3): p. 249-257.

[6] Kutsch, W., Telemetry in insects: the "intact animal approach". Theory in Biosciences, 1999. 118(1): p. 29-53.

[7] Nations, C.S. and R.C. Anderson-Sprecher, Estimation of animal location from radio telemetry data with temporal dependencies. Journal of Agricultural Biological and Environmental Statistics, 2006. 11(1): p. 87-105.

[8] Salvatori, V., et al., Estimating temporal independence of radio-telemetry data on animal activity. Journal of Theoretical Biology, 1999. 198(4): p. 567-574.

[9] Walisser, J., et al., Optimizing Telemetry Stock Animal Quality: Implementation of Monthly Signal Checks and Assessment of Transmitter Battery Life. Journal of the American Association for Laboratory Animal Science, 2010. 49(5): p. 721-721.

[10] Ko, W.H., et al., Studies of MEMS Acoustic Sensors as Implantable Microphones for Totally Implantable Hearing-Aid Systems. IEEE Transactions on Biomedical Circuits and Systems, 2009. 3(5): p. 277-285.

[11] Yoon, K.W., et al., Telemetry capsule for pressure monitoring in the gastrointestinal tract. Ieice Transactions on Fundamentals of Electronics Communications and Computer Sciences, 2006. E89a(6): p. 1699-1700.

[12] Browning, C., et al., A New Pressure Sensitive Ingestible Radio Telemetric Capsule. The Lancet, 1981. 318(8245): p. 504-505. 
[13] Mackay, R.S. and B. Jacobson, Endoradiosonde. Nature, 1957. 179(4572): p. 1239-1240.

[14] Connell, A.M. and E.N. Rowlands, Wireless Telemetering from the Digestive Tract. Gut., 1960. 1(3): p. 266-272.

[15] Banerjee, R. and D.N. Reddy, Bravo capsule pH monitoring. American Journal of Gastroenterology, 2006. 101(4): p. 906-906.

[16] Belafsky, P.C., et al., Wireless $p H$ testing as an adjunct to unsedated transnasal esophagoscopy: The safety and efficacy of transnasal telemetry capsule placement. Otolaryngology-Head and Neck Surgery, 2004. 131(1): p. 26-28.

[17] Chaw, C.S., E. Yazaki, and D.F. Evans, The effect of $p H$ change on the gastric emptying of liquids measured by electrical impedance tomography and $\mathrm{pH}$-sensitive radiotelemetry capsule. International Journal of Pharmaceutics, 2001. 227(1-2): p. 167-175.

[18] Pandolfino, J.E., Bravo capsule $\mathrm{pH}$ monitoring. American Journal of Gastroenterology, 2005. 100(1): p. 8-10.

[19] Holloway, R.H., Capsule pH monitoring: is wireless more? Gut, 2005. 54(12): p. 1672-1673.

[20] Thorne, P.S., C.P. Yeske, and M.H. Karol, Monitoring Guinea Pig Core Temperature by Telemetry during Inhalation Exposures. Toxicological Sciences, 1987. 9(3): p. 398-408.

[21] O'Brien, C., et al., Telemetry pill measurement of core temperature in humans during active heating and cooling. Medicine and Science in Sports and Exercise, 1998. 30(3): p. 468472.

[22] Iddan, G., et al., Wireless capsule endoscopy. Nature, 2000. 405(6785): p. 417-417.

[23] Svarta, S., et al., Diagnostic yield of repeat capsule endoscopy and the effect on subsequent patient management. Canadian Journal of Gastroenterology, 2010. 24(7): p. 441-444.

[24] Spada, C., et al., Capsule endoscopy in Italy: An unbalanced review of the literature. International Journal of Technology Assessment in Health Care, 2010. 26(3): p. 354356.

[25] Spada, C., et al., PillCam Colon Capsule Endoscopy (PCCE) for Colon Exploration: A Single Centre Italian Experience. Gastrointestinal Endoscopy, 2010. 71(5): p. Ab203-Ab203.

[26] Woo, S.H., et al., High Speed Receiver for Capsule Endoscope. Journal of Medical Systems, 2010. 34(5): p. 843-847.

[27] Menciassi, A., et al. Single and multiple robotic capsules for endoluminal diagnosis and surgery. in Biomedical Robotics and Biomechatronics, 2008. BioRob 2008. 2nd IEEE RAS E EMBS International Conference on. 2008.

[28] Quirini, M., et al., Design and Fabrication of a Motor Legged Capsule for the Active Exploration of the Gastrointestinal Tract. Mechatronics, IEEE/ASME Transactions on, 2008. 13(2): p. 169-179.

[29] Byungkyu, K., et al. Inchworm-Like Microrobot for Capsule Endoscope. in Robotics and Biomimetics, 2004. ROBIO 2004. IEEE International Conference on. 2004.

[30] Elisa, B. and et al., Evaluation of friction enhancement through soft polymer micro-patterns in active capsule endoscopy. Measurement Science and Technology, 2010. 21(10): p. 105802.

[31] Quirini, M., et al., Feasibility proof of a legged locomotion capsule for the GI tract. Gastrointestinal Endoscopy, 2008. 67(7): p. 1153-1158.

[32] Woo, S.H., et al., Implemented edge shape of an electrical stimulus capsule. International Journal of Medical Robotics and Computer Assisted Surgery, 2009. 5(1): p. 59-65. 
[33] Park, H.J., et al., New method of moving control for wireless endoscopic capsule using electrical stimuli. Ieice Transactions on Fundamentals of Electronics Communications and Computer Sciences, 2005. E88a(6): p. 1476-1480.

[34] Glass, P., E. Cheung, and M. Sitti, A Legged Anchoring Mechanism for Capsule Endoscopes Using Micropatterned Adhesives. Biomedical Engineering, IEEE Transactions on, 2008. 55(12): p. 2759-2767.

[35] Woo, S.H., T.W. Kim, and J.H. Cho, Stopping mechanism for capsule endoscope using electrical stimulus. Medical \& Biological Engineering \& Computing, 2010. 48(1): p. 97-102.

[36] Nagaoka, T. and A. Uchiyama. Development of a small wireless position and bleeding detection sensor. in Microtechnology in Medicine and Biology, 2005. 3rd IEEE/EMBS Special Topic Conference on. 2005.

[37] Menciassi, A. and P. Dario. Miniaturized robotic devices for endoluminal diagnosis and surgery: A single-module and a multiple-module approach. in Engineering in Medicine and Biology Society, 2009. EMBC 2009. Annual International Conference of the IEEE. 2009.

[38] http://www.intromedic.com/.

[39] Gao, Y.J., et al., Endoscopic capsule placement improves the completion rate of small-bowel capsule endoscopy and increases diagnostic yield. Gastrointestinal Endoscopy, 2010. 72(1): p. 103-108.

[40] Kim, H.M., et al., A Pilot Study of Sequential Capsule Endoscopy Using MiroCam and PillCam SB Devices with Different Transmission Technologies. Gut and Liver, 2010. 4(2): p. 192-200.

[41] Lee, J., et al., CPLD based bi-directional wireless capsule endoscopes. Ieice Transactions on Information and Systems, 2007. E90d(3): p. 694-697.

[42] Yuan, G., et al. Low power ultra-wideband wireless telemetry system for capsule endoscopy application. in Robotics Automation and Mechatronics (RAM), 2010 IEEE Conference on. 2010.

[43] Thone, J., et al., Design of a 2 Mbps FSK near-field transmitter for wireless capsule endoscopy. Sensors and Actuators a-Physical, 2009. 156(1): p. 43-48.

[44] Xinkai, C., et al., A Wireless Capsule Endoscope System With Low-Power Controlling and Processing ASIC. Biomedical Circuits and Systems, IEEE Transactions on, 2009. 3(1): p. 11-22.

[45] Kfouri, M., M. Kfouri, and M. Kfouri, Toward a miniaturised wireless fluorescence-based diagnostic imaging system. IEEE J. Selected Topics in Quantum Electronics, 2008. 14.

[46] MacKay, R.S., Bio-Medical Telemetry: Sensing and Transmitting Biological Information from Animals and Man. 1998: John Wiley \& Sons. 


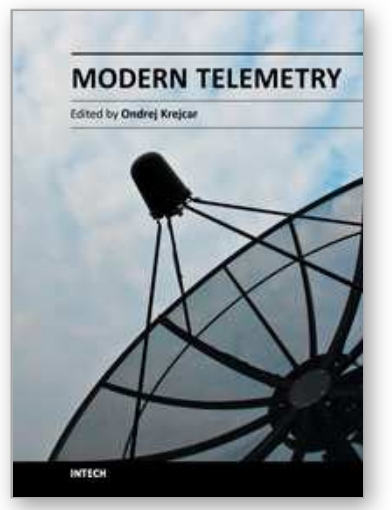

\author{
Modern Telemetry \\ Edited by Dr. Ondrej Krejcar
}

ISBN 978-953-307-415-3

Hard cover, 470 pages

Publisher InTech

Published online 05, October, 2011

Published in print edition October, 2011

Telemetry is based on knowledge of various disciplines like Electronics, Measurement, Control and Communication along with their combination. This fact leads to a need of studying and understanding of these principles before the usage of Telemetry on selected problem solving. Spending time is however many times returned in form of obtained data or knowledge which telemetry system can provide. Usage of telemetry can be found in many areas from military through biomedical to real medical applications. Modern way to create a wireless sensors remotely connected to central system with artificial intelligence provide many new, sometimes unusual ways to get a knowledge about remote objects behaviour. This book is intended to present some new up to date accesses to telemetry problems solving by use of new sensors conceptions, new wireless transfer or communication techniques, data collection or processing techniques as well as several real use case scenarios describing model examples. Most of book chapters deals with many real cases of telemetry issues which can be used as a cookbooks for your own telemetry related problems.

\title{
How to reference
}

In order to correctly reference this scholarly work, feel free to copy and paste the following:

Jin-Ho Cho and Sang Hyo Woo (2011). Communication Strategies for Various Types of Swallowable Telemetry Capsules, Modern Telemetry, Dr. Ondrej Krejcar (Ed.), ISBN: 978-953-307-415-3, InTech, Available from: http://www.intechopen.com/books/modern-telemetry/communication-strategies-for-various-types-ofswallowable-telemetry-capsules

\section{INTECH}

open science | open minds

\section{InTech Europe}

University Campus STeP Ri

Slavka Krautzeka 83/A

51000 Rijeka, Croatia

Phone: +385 (51) 770447

Fax: +385 (51) 686166

www.intechopen.com

\section{InTech China}

Unit 405, Office Block, Hotel Equatorial Shanghai

No.65, Yan An Road (West), Shanghai, 200040, China

中国上海市延安西路 65 号上海国际贵都大饭店办公楼 405 单元

Phone: +86-21-62489820

Fax: $+86-21-62489821$ 
(C) 2011 The Author(s). Licensee IntechOpen. This is an open access article distributed under the terms of the Creative Commons Attribution 3.0 License, which permits unrestricted use, distribution, and reproduction in any medium, provided the original work is properly cited. 